\title{
A LOW FREQUENCY GAIN IMPROVEMENT OF TAPERED SLOT VIVALDI ANTENNA WITH BAND-NOTCH BASED ON COMPLEMENTARY SPLIT RING RESONATOR CSRR
}

\author{
${ }^{*}$ Karrar S. Hasan ${ }^{1}$
}

Zaid A. Abdul Hassain²

1) M.Sc., Student Electrical Engineering Department, Mustansiriyah University, Baghdad, Iraq.

2) Assistant Prof., Electrical Engineering Department, Mustansiriyah University, Baghdad, Iraq.

\begin{abstract}
A compact tapered slot Vivaldi antenna TSVA with improved low frequency gain and band notch characteristics for WLAN band in the range of 5.15$5.825 \mathrm{GHz}$ is presented. Based on the corrugation in the patch edges, the gain of proposed antenna is enhanced in low frequency range about $1.53 \mathrm{~dB}$ to minimize the electromagnetic overlap with narrow band WLAN communication, a complementary split ring resonator CSRR is etched out near the microstrip feed line in order to obtain a WLAN band notch. The antenna is simulated using computer simulation technology software (CST) then, fabricated on $1.5 \mathrm{~mm}$ thickness FR4 $\left(\epsilon_{r}=4.4\right)$, $38 \times 36 \mathrm{~mm}^{2}$ substrate.
\end{abstract}

Keywords: CST; Vivaldi antenna with band notch.

\section{Introduction}

The Federal Communication Commission (FCC) allocate the frequency band from (3.1 to 10.6) $\mathrm{GHz}$ for commercial ultrawideband (UWB) communications in 2002, due to UWB has attractive properties such as high speed data rate transfer, high accuracy and wide bandwidth ,it is used in wireless communications and radar applications [1][3].Gibson first introduced Taper slot Vivaldi antenna(TSVA) in 1979, the Due to its naturalistic broad impedance bandwidth, several Vivaldi antennas have been researched and designed [4]-[6]. the Vivaldi antenna has many advantages such as, it has low cross polarization and moderate end-fire gain feature. However, Vivaldi antennas are face many problems including the difficulty of reducing the antenna size and maintaining wide impedance bandwidth with steady radiation performance in the complete band. Since there are many present narrowband services which use frequency bands within the range of UWB (3.1-10.6GHz), problem of the electromagnetic overlaps is very serious for UWB systems operation. many researchers done on solve this problem and tried to reduce the electromagnetic overlaps with other narrow band communication system. Several techniques presented in UWB antennas with band notch behavior obtained by employing different modifications with etching out slots on the patch surface or by defecting the ground plane [7]-[12]. In [7], Bow-tie UWB omnidirectional antenna has been inserted SIR to reject interference with narrow band. The second method is to etch slot with omnidirectional UWB antenna in [8]. In [9],[10], An SRR have been introduced into a monopole UWB omnidirectional antenna to avoid interference and achieve band notch properties. In [11],[12],

*Corresponding Author: sadiq.karrar@yahoo.com 
Vivaldi UWB directional antenna with band notch properties.

In this paper, a built-in TSVA with improved low frequency gain having notched task in the WLAN (4.989-5.9485 GHz) based on CSRR is proposed. By loading the rectangular and triangular slots at the brims to focusing the electric field distribution towards the slot in the low and high frequency band.

\section{Antenna Design and Analysis the distribution of current after add (slots and CSSR)}

The configurations of four design of TSVA are shown in Fig .1. The antenna size is $38 \mathrm{~mm} \times$ $36 \mathrm{~mm}$ printed on $1.5 \mathrm{~mm}$ FR4 dielectric substrate $\left(\varepsilon_{r}=4.4\right)$ this size is small compared to UWB Vivaldi antennas as in [11]-[12]. The traditional TSVA is considered as a reference antenna using a diamond slot instead of circle as shown in Fig.1. The antenna consists of: a radiating slot, a microstrip line to slot-line transition structure, and a radial stub at the microstrip feed line as shown in Fig .2. In order to obtain an antenna with stable matched over UWB band a suitable microstrip line to slotline transition is designed. The exponential tapered curve used in the TVA as [12]:

$$
\begin{gathered}
x=c 1 * e^{r * z}+c 2 \\
c 1=\frac{(x 2-x 1)}{\left(e^{r * z 2}-e^{r * z 1}\right)} \\
c 2=\frac{\left(x 1 e^{r * z 2}-x 2 e^{r * Z 1}\right)}{\left(e^{r * z 2}-e^{r * z 1}\right)}
\end{gathered}
$$

Where $\mathrm{x}$ is the space from the central axis to the exponential brim, ranging from $\mathrm{x} 1$ to $\mathrm{x} 2$ identical to $\mathrm{z}$ changing from $\mathrm{z} 1$ to $\mathrm{z} 2$ and $\mathrm{r}$ presents the exponential rate 0.17 . A pair of symmetrical Rectangular slots (RS) are drilled on the outer brims as shown in Fig .3. A triple of different sizes symmetrical triangular shaped slots (TS) is drilled on the outer brims as shown in Fig.4

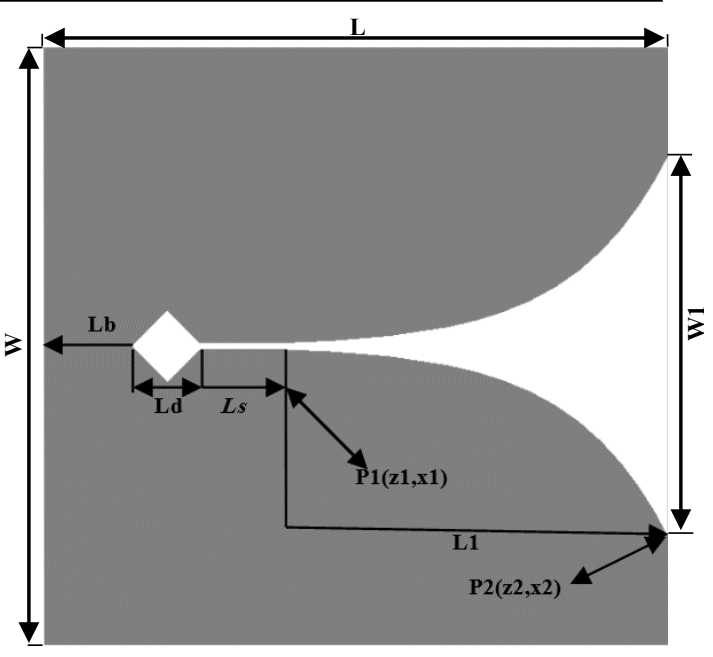

Figure1. Design the taper slot Vivaldi antenna.

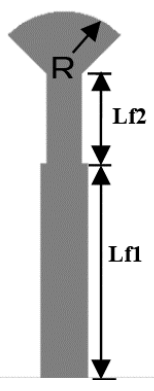

Figure 2. Back view of taper slot Vivaldi antenna

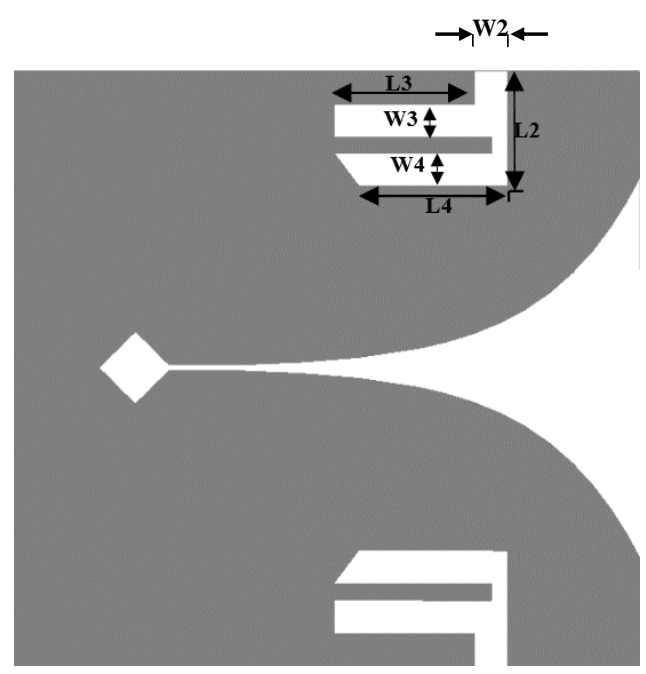

Figure.3. Vivaldi antenna after etching rectangular slots 


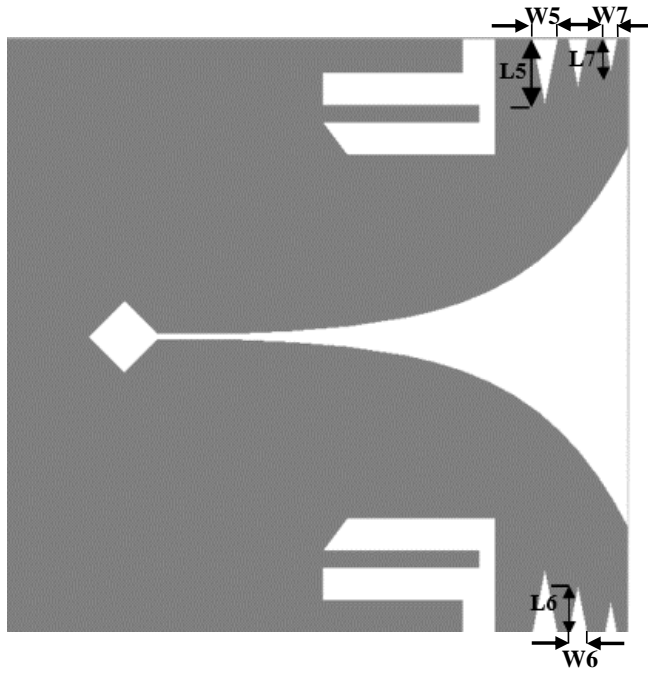

Figure 4. Vivaldi antenna after etching rectangular and triangular slots.

furthermore, in order to reduce the electromagnetic interference with narrow band WLAN communication $(5.15 \mathrm{GHz}-5.35 \mathrm{GHz}$ ,5.725-5.825GHz).a complementary split ring resonator is etched out near the microstrip feed region as shown in in Fig.5.The band-notched frequency of the complementary spilt ring (CSRR) is given is calculated as:

$$
f_{\text {notch }}=\frac{C}{2 * L_{c} * \sqrt{\varepsilon_{e f f}}}(4)
$$

Fnotch is the notch band frequency, $\mathrm{C}$ the is speed of light, Lc is the total length of CSRR, $\varepsilon_{e f f}$ is the effective dielectric constant.

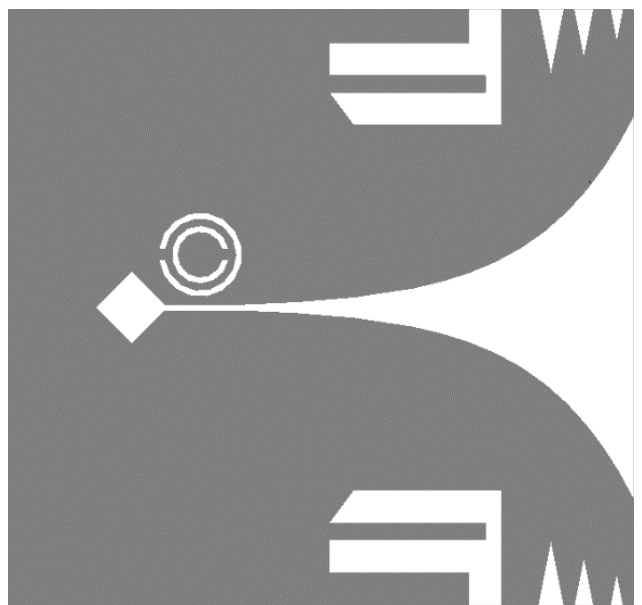

Figure 5. Vivaldi antenna after etching slots and load CSRR.

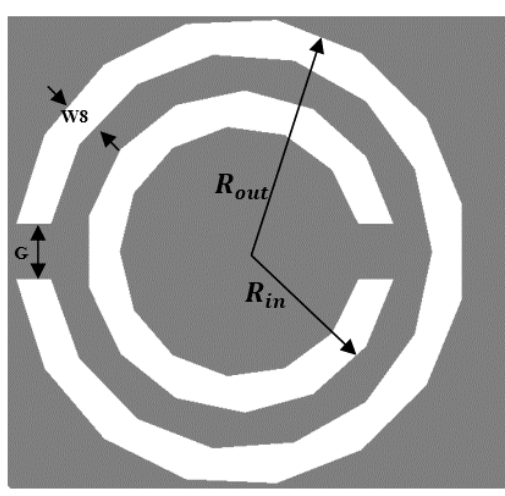

Figure 6. The design of CSRR.

The values in this table (1) were chosen during the study of properties except for CSRR values in equation (4).

Table 1. The values of optimum antenna parameters.

\begin{tabular}{|l|l|l|l|}
\hline parameters & $\begin{array}{l}\text { values } \\
(\mathrm{mm})\end{array}$ & parameters & $\begin{array}{l}\text { values } \\
(\mathrm{mm})\end{array}$ \\
\hline L & 38 & $\mathrm{~W}$ & 36 \\
\hline L1 & 24 & $\mathrm{~W} 1$ & 23 \\
\hline L2 & 7 & W2 & 2 \\
\hline L3 & 8.5 & W3 & 2 \\
\hline L4 & 9 & W4 & 2 \\
\hline L5 & 4 & W5 & 1.6 \\
\hline L6 & 3 & W6 & 1.2 \\
\hline L7 & 2 & W7 & 0.8 \\
\hline Lf1 & 13 & W8 & 0.4 \\
\hline Lf2 & 5.5 & R & 4.8 \\
\hline Ls & 4.5 & $R_{\text {in }}$ & 1.76 \\
\hline Ld & 4.2 & $R_{\text {out }}$ & 2.56 \\
\hline Lb & 5.3 & G & 0.6 \\
\hline
\end{tabular}


The maximum surface current distribution should be concentrated along the inner brims of the tapered slot in order to produce high gain end fire radiation pattern. For traditional TVA the surface current is distributed toward the inner brims and toward the outer brims as will show later as shown in Fig .7. (a). The maximum surface current distribution concentrates along the inner edges of rectangular slots at $\mathrm{f}=3 \mathrm{GHz}$ as shown in Fig.7(b). And therefore, results good radiation in the end fire direction. The maximum surface current distribution along the inner edges of triangular slots at $\mathrm{f}=10 \mathrm{GHz}$, results good radiation in the end fire direction as shown in Fig.7(c).

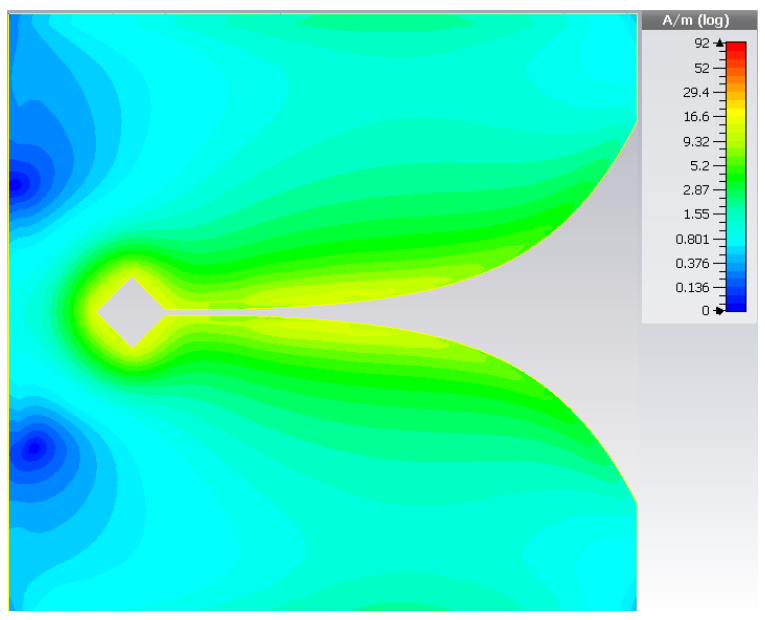

(a)

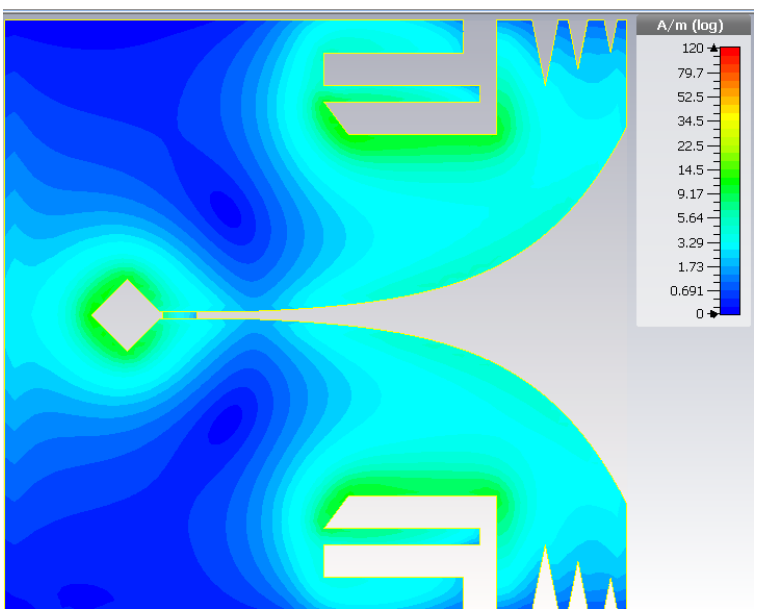

(b)

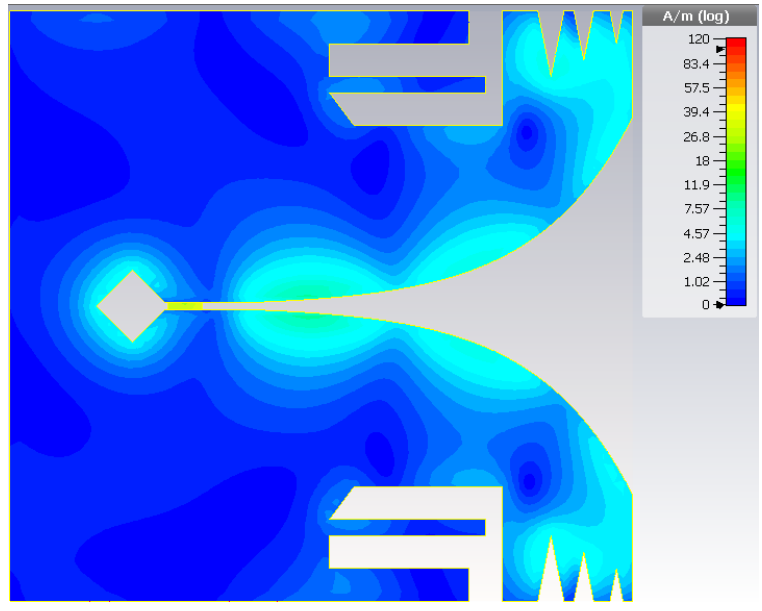

(c)

Figure 7(a, b \& c). Simulate the distribution before add CSRR at $3 \mathrm{GHz}$ without slots, $3 \mathrm{GHz}$ after add rectangular slots and10GHz. After add rectangular and triangular slots.

Fig .8(a) shows the distribution of current at $\mathrm{f}=3 \mathrm{GHz}$ after add CSRR to the Vivaldi antenna and it also shows that the current distribution is still concentrated at the inner edges of the rectangular slots and CSRR only effect on the antenna at $\mathrm{f}=5.5 \mathrm{GHz}$, Fig.8(b) shows the distribution of current at $\mathrm{f}=5.5 \mathrm{GHz}$, it shows that the distribution density of current is more concentrated on the surface of the CSRR near the feed area and Fig.8(c) shows the current distribution at $\mathrm{f}=10 \mathrm{GHz}$ after add CSRR is still concentrated at the inner edges for triangular slots.

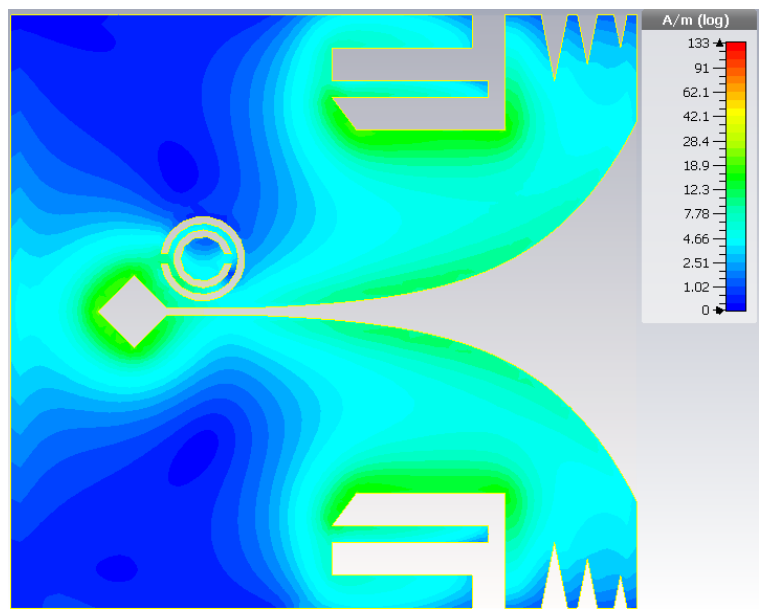

(a) 


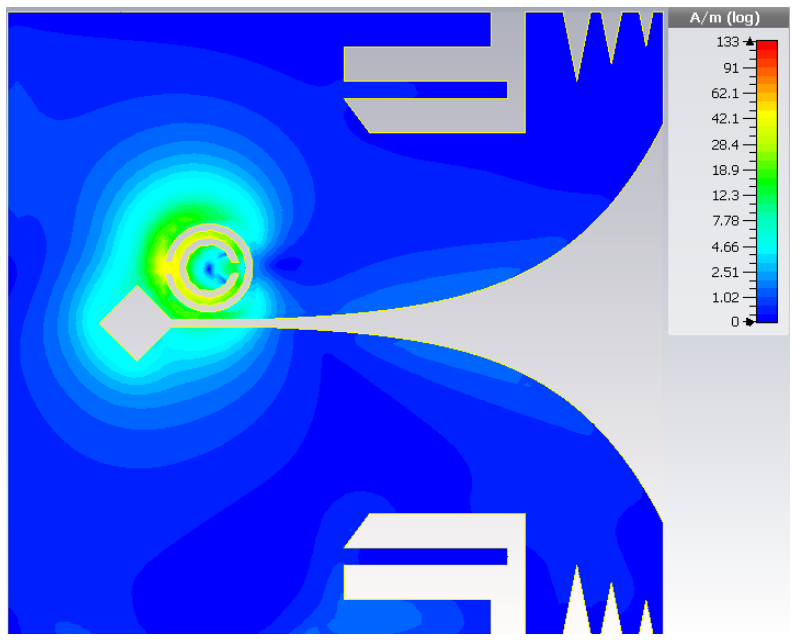

(b)

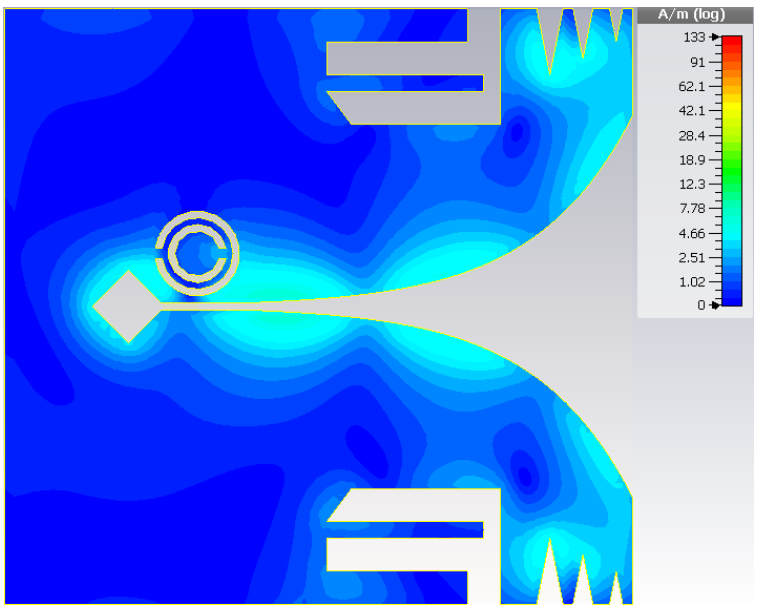

(c)

Figure 8(a,b \& c). Simulate surface current distribution after add CSRR at $3 \mathrm{GHz}, 5.5 \mathrm{GHz}$. \& $10 \mathrm{GHz}$.

\section{The simulation results of (return loss) $(\mathrm{S} 1,1)$ and the (Gain)}

Fig .9 (a) shown simulated the compare results S11 of the Vivaldi antenna with rectangular slots and Vivaldi antenna without rectangular slots and CSRR, note that after add rectangular slots (RS) $\mathrm{S} 11<-10 \mathrm{~dB}$ range from 2.937 to $12 \mathrm{GHz}$ and so this can cover UWB entire, in Fig.9(b) show the results after add triangular slots (TS) to the Vivaldi antenna note that impedance bandwidth ranging from 2.956 $\mathrm{GHz}$ to $12 \mathrm{GHz}$ and Fig.9(c.1) note that the impedance bandwidth after load CSRR to the Vivaldi antenna near the microstrip feed line ranging from $3.0225 \mathrm{GHz}$ to $11.573 \mathrm{GHz}$ except the band notch $\mathrm{S} 11>-10 \mathrm{~dB}$ ranging from
$4.989 \mathrm{GHz}$ to $5.9485 \mathrm{GHz}$ and so become Vivaldi UWB antenna with band notch Shown in Fig .9(c.2)-(c.3), in Fig .9(c.4) note that the Fnotch $=5.464 \mathrm{GHz}$ and the value of the gain is negative.

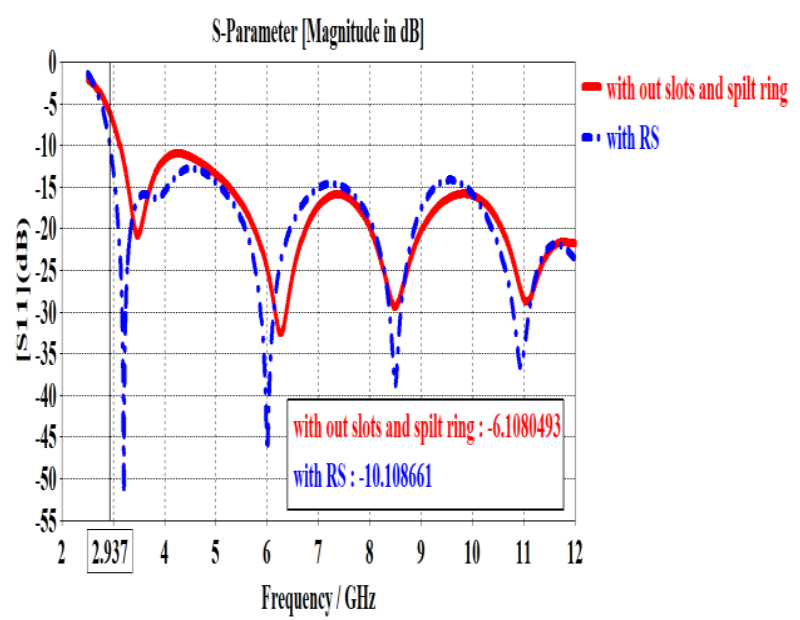

(a)

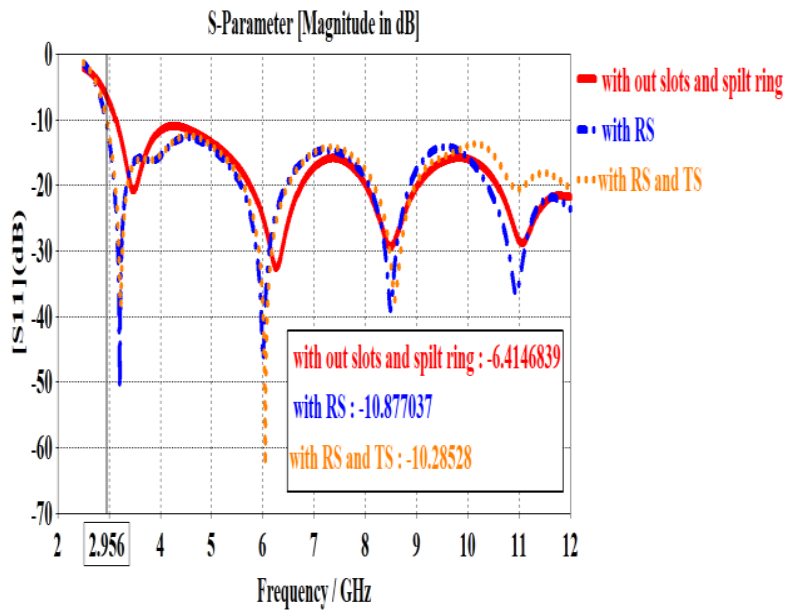

(b)

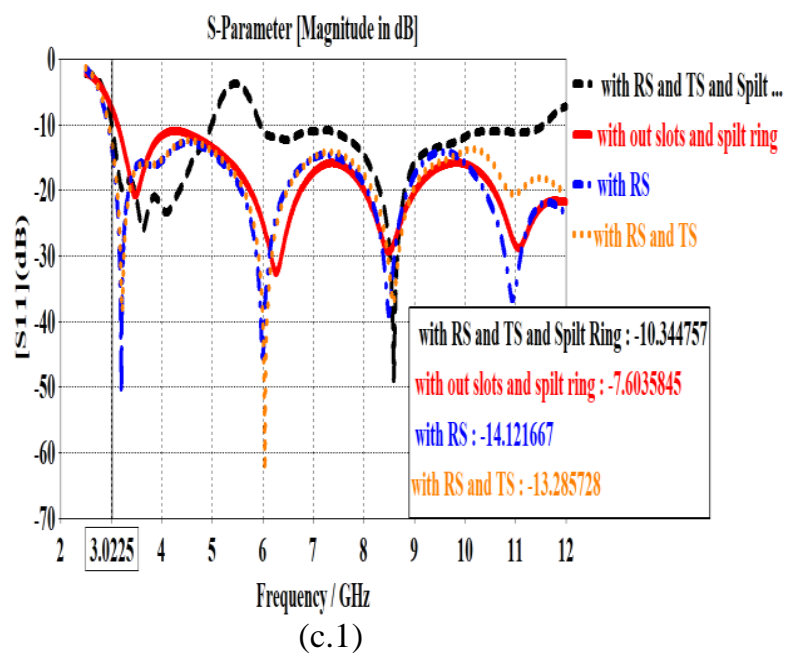




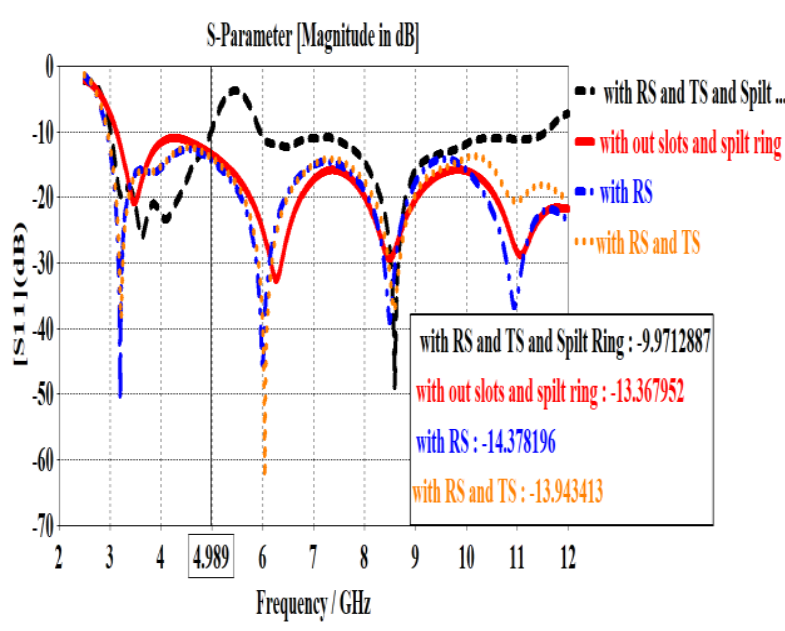

(c.2)

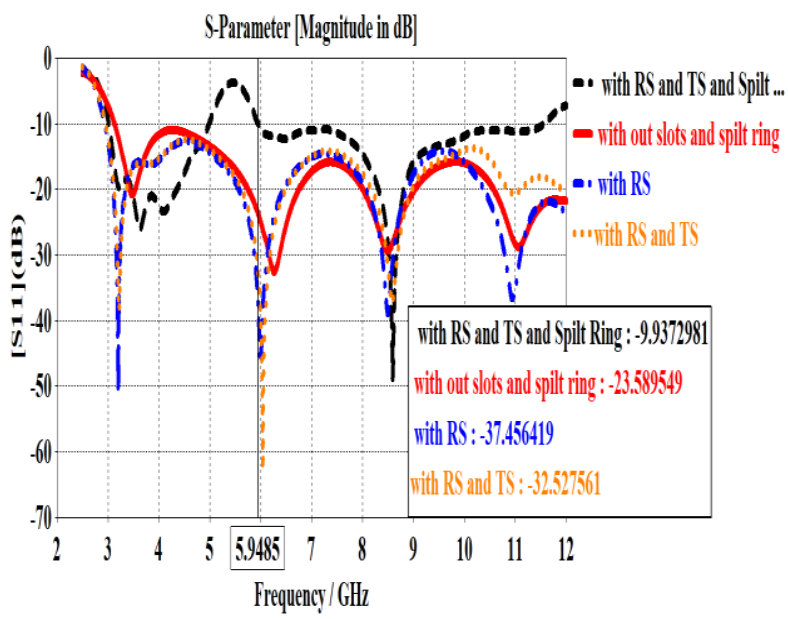

(c.3)

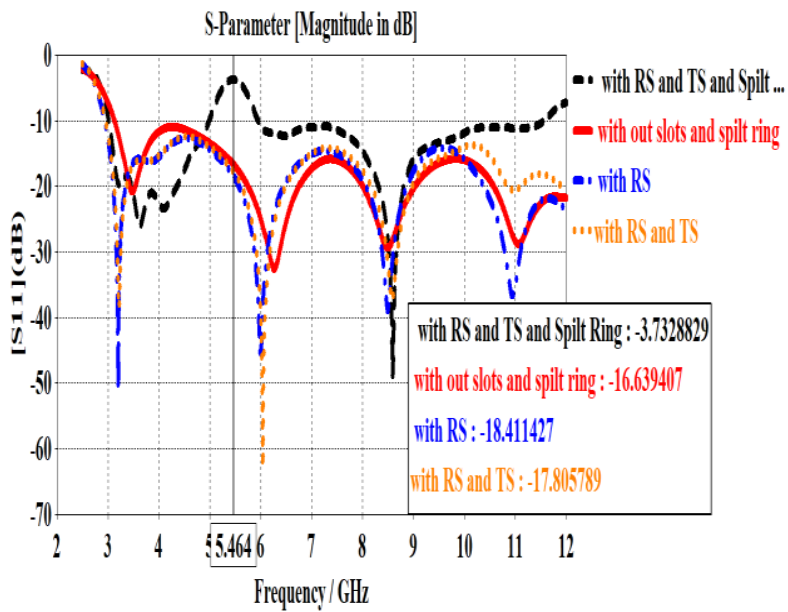

(c.4)

Figure 9 (a, b, c.1, c.2, c.3, \&c.4). Simulated the S11 $(\mathrm{dB})$ at Vivaldi antenna with rectangular slots, Vivaldi antenna with rectangular and triangular slots \& Vivaldi antenna with slots and CSRR.
The Fig .10(a). shows that the gain at low frequency (3.1) $\mathrm{GHz}$ is improved after adding rectangular slots to the traditional Vivaldi antenna by $(1.53 \mathrm{~dB})$,in Fig .10(b) shows that the gain at high frequency is improved after adding triangular shaped slots to the Vivaldi antenna by $(1.26 \mathrm{~dB})$ and Fig .10(c.1) shows that the gain at $(\mathrm{F}$ notch $=-3.35 \mathrm{~dB})$ after load the CSRR to the Vivaldi antenna and become band notch region and as well as gain at low frequency improved by $(0.735 \mathrm{~dB})$ as shown in the Fig.10(c.2).

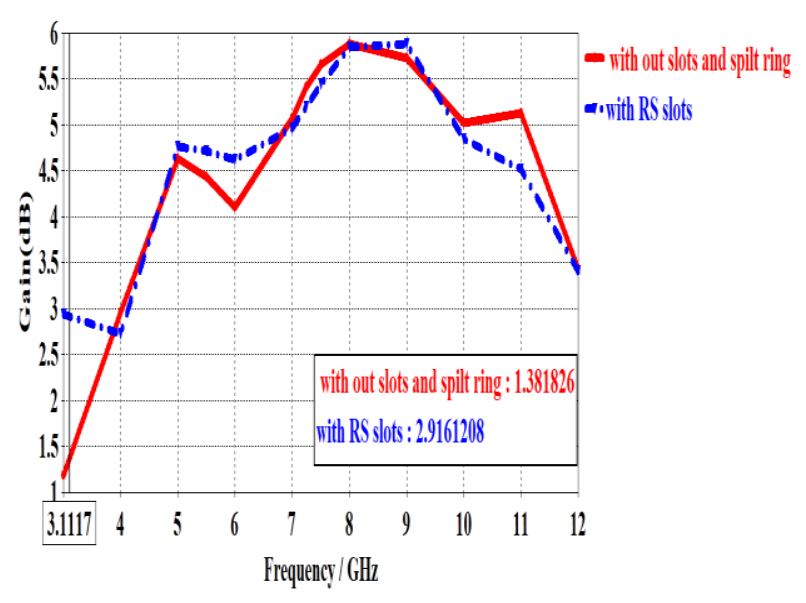

(a)

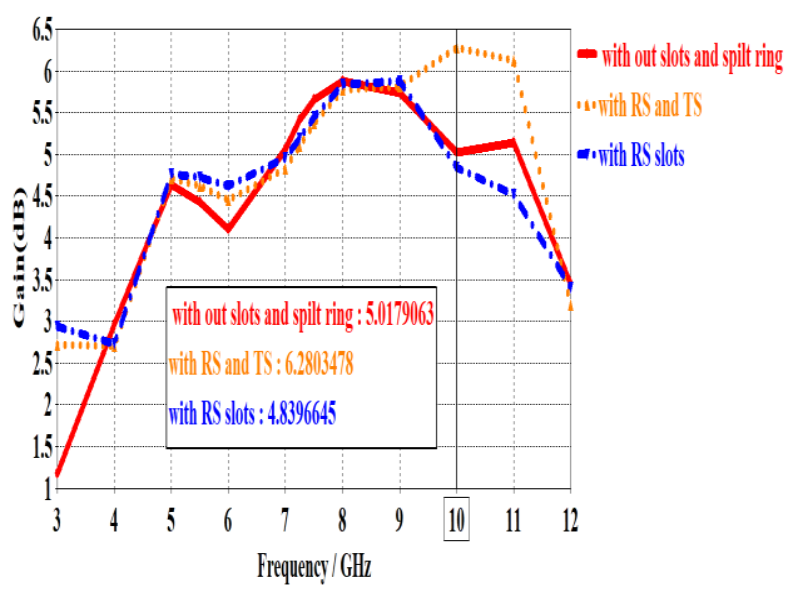

(b) 


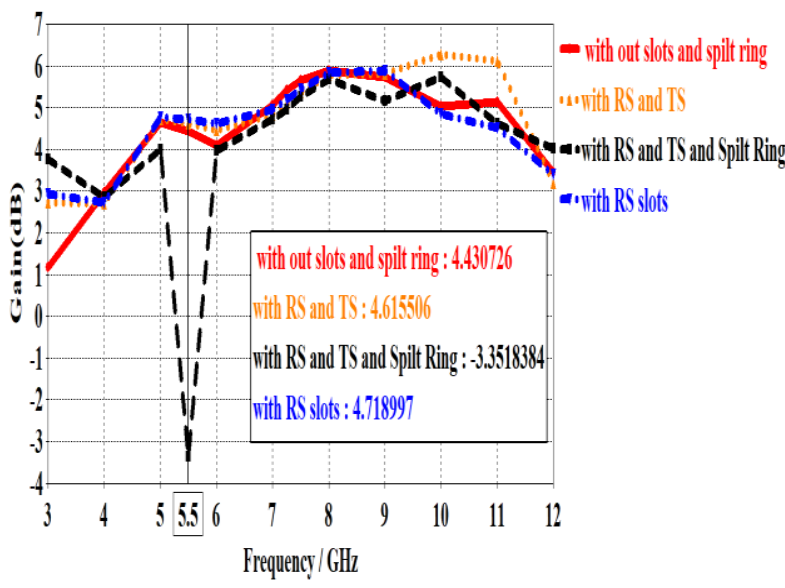

(c.1)

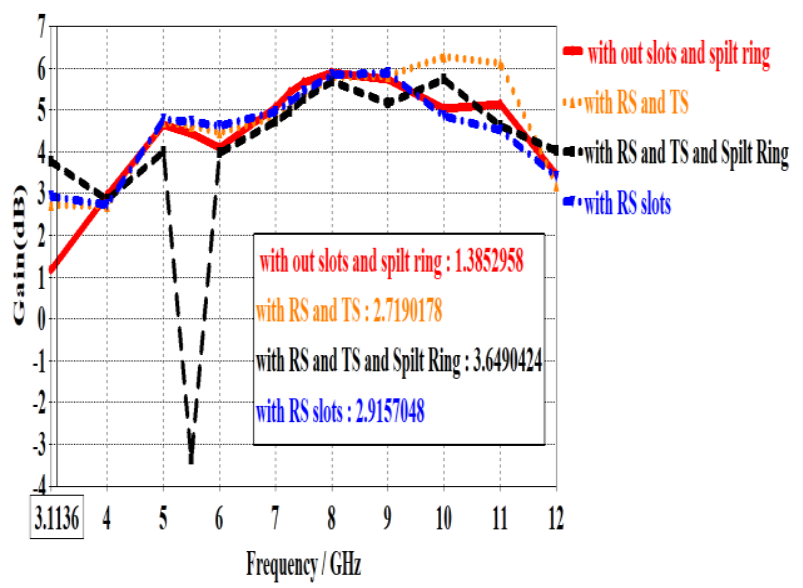

(c.2)

Figure 10(a, b \& c). Simulated the Gain $(\mathrm{dB})$ of Vivaldi antenna with, rectangular slots, rectangular and triangular slots \& slots and CSRR.

\section{The simulation results of Directivity}

The Fig .11(a). shows that the directivity at low frequency (3.1) $\mathrm{GHz}$ is improved after adding rectangular slots to the traditional Vivaldi antenna by (2.95dBi), in Fig .11(b) shows that the directivity at high frequency is improved after adding triangular shaped slots to the Vivaldi antenna by (1.28dBi) and Fig .11(c) shows that the directivity at $\mathrm{F}$ notch reduced by( $0.858 \mathrm{dBi}$ ) after load the CSRR to the Vivaldi antenna.

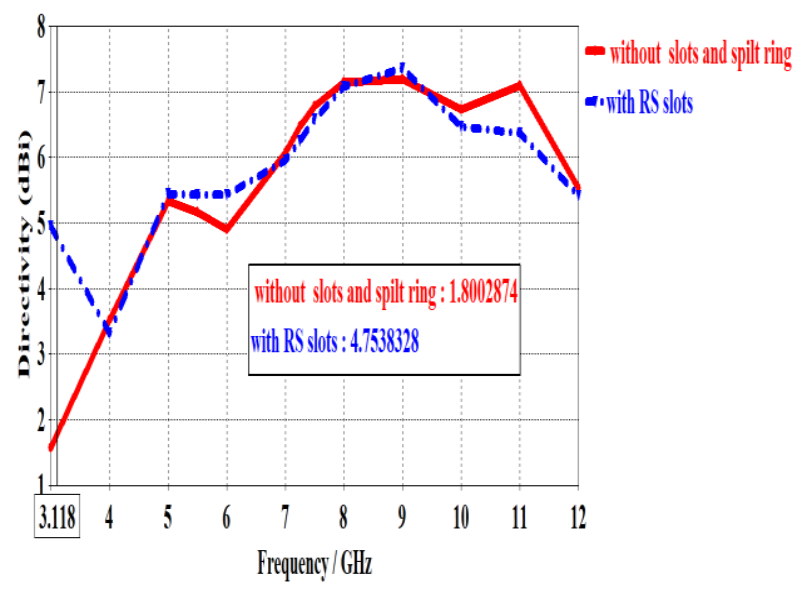

(a)

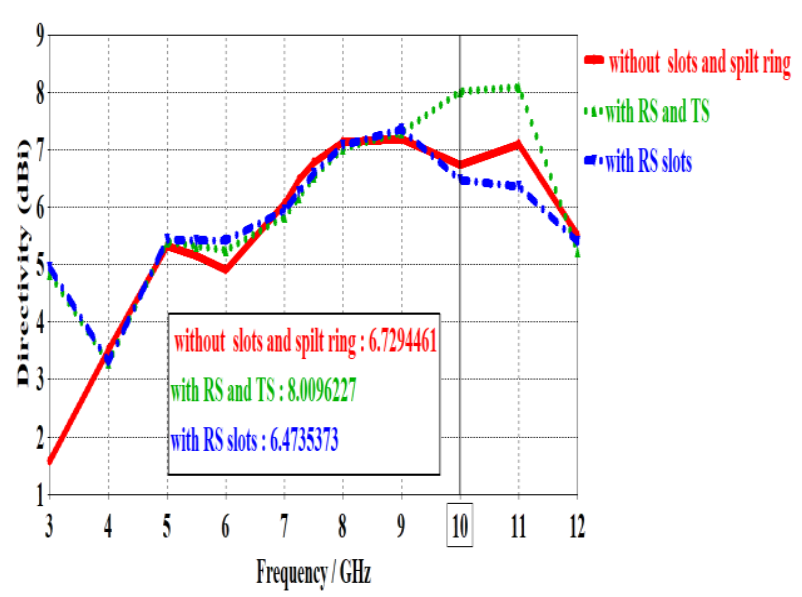

(b)

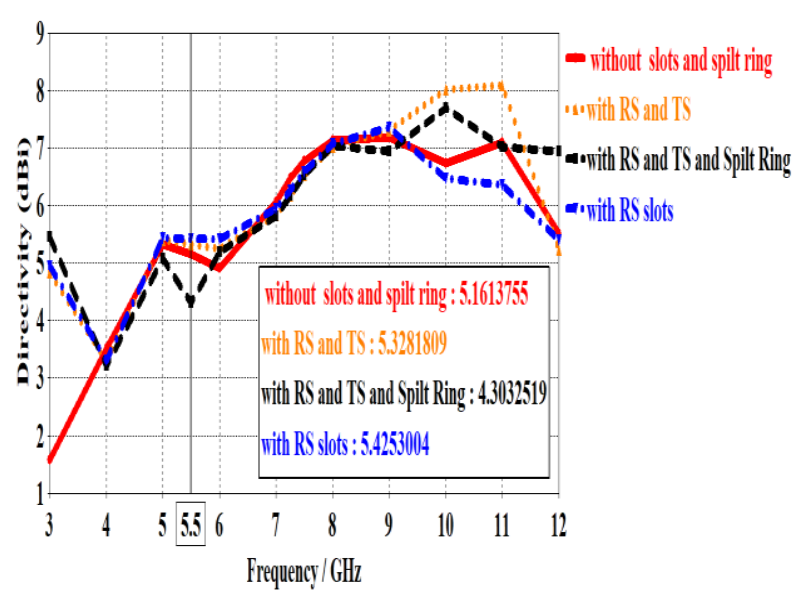

(c)

Figure 11(a, b \& c). Simulated the Directivity (dBi) of Vivaldi antenna with, rectangular slots, rectangular and triangular slots \& slots and CSRR. 


\section{The simulation results of the radiation Vivaldi antenna pattern}

in Fig .12(a) shows the radiation of the Vivaldi antenna at $\mathrm{f}=3 \mathrm{GHz}$ before add slots is not in the end fire direction and shows that the radiation improved after add rectangular slots to Vivaldi antenna at $\mathrm{f}=3 \mathrm{GHz}$ and become in directional of end fire. Fig .12(b) shows that the radiation the at $\mathrm{f}=5.5 \mathrm{GHz}$ after add CSRR become very bad and become is in not direction end fire in comparison with the radiation of Vivaldi antenna before load CSRR at $\mathrm{f}=5.5 \mathrm{GHz}$, and so avoids the interference with the narrow band WLAN because the interference effect the performance of UWB applications.
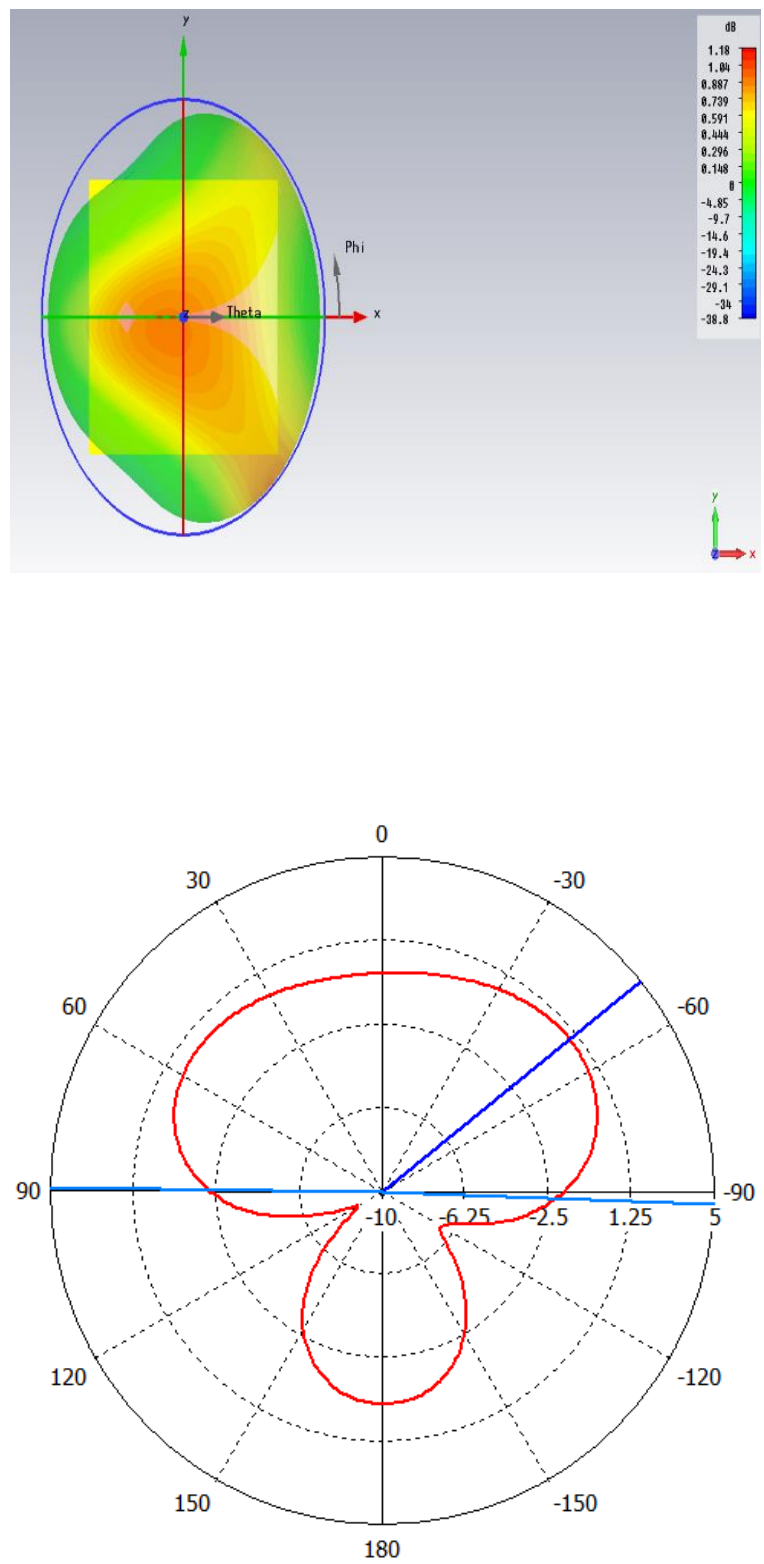
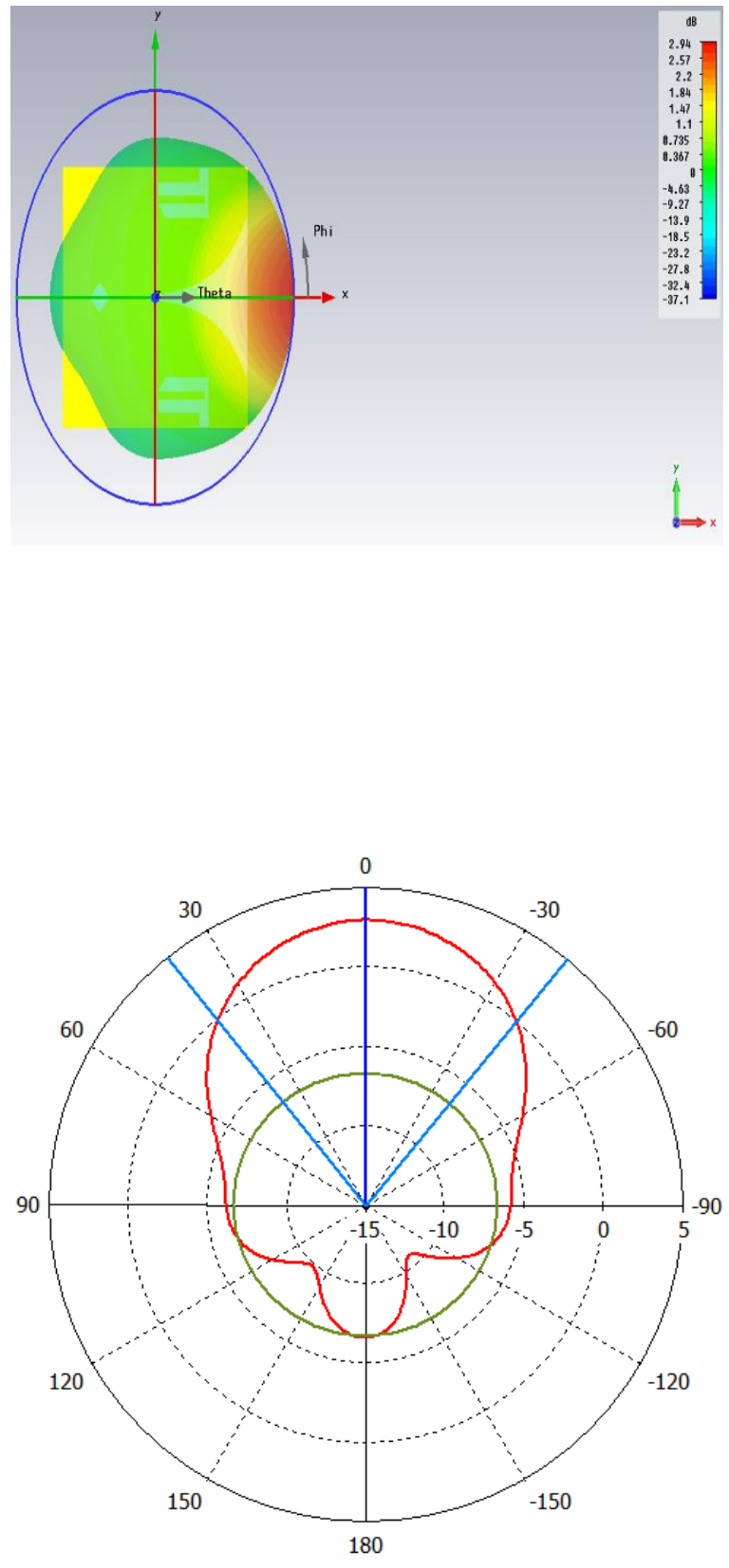

(a)

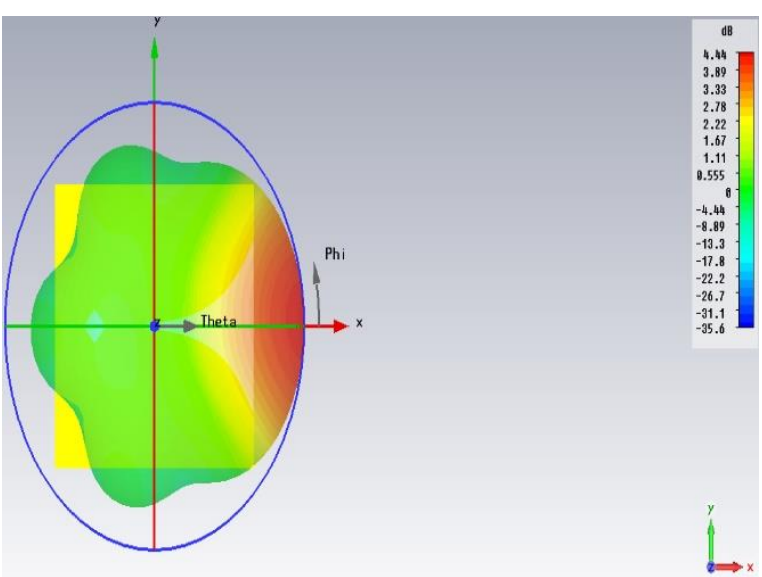



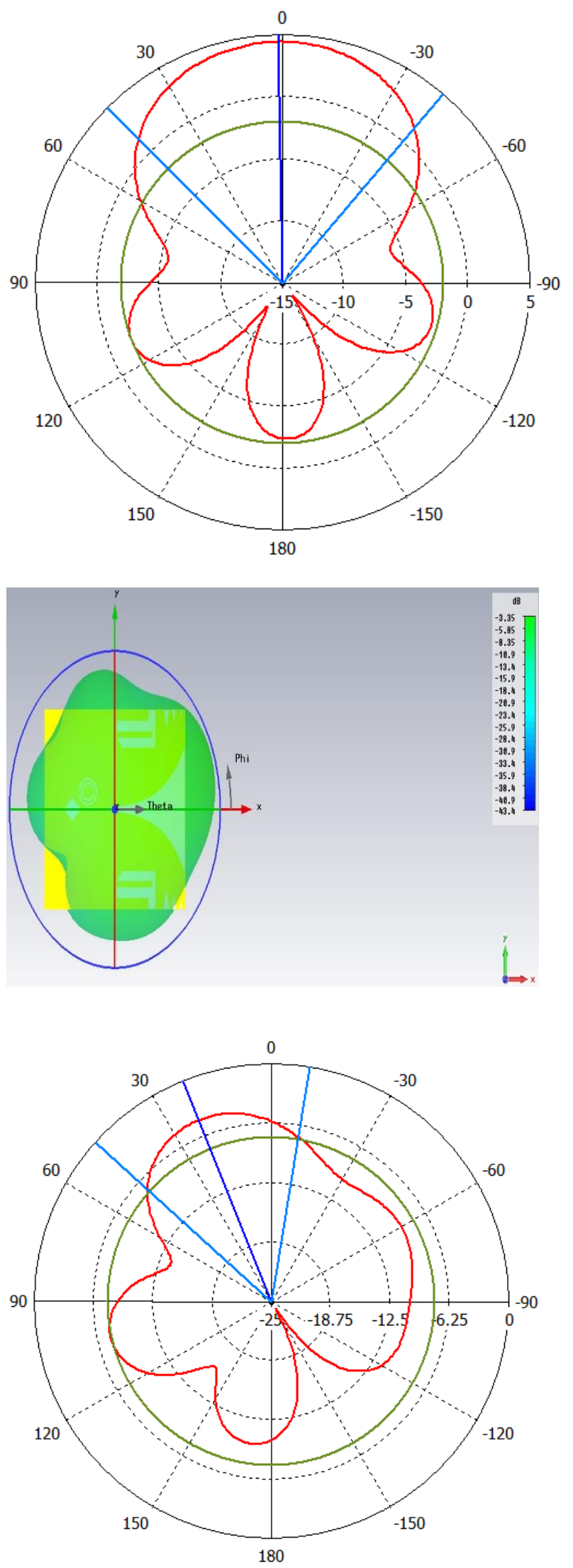

(b)

Figure.12 (a \& b). Simulate the radiation pattern of the Vivaldi antenna at at $3 \mathrm{GHz} \& 5.5 \mathrm{GHz}$.

\section{Conclusions}

In this work, UWB Vivaldi antenna etched the rectangular and a triangular slots at the brims to focusing the distribution of electric field towards the slots in the low and high frequency band and in order to improvement the gain and the radiation, note that the radiation become at low frequency in end fire direction and the impedance bandwidth $\mathrm{S} 11<-10 \mathrm{~dB}$ ranging from $2.956 \mathrm{GHz}$ to $12 \mathrm{GHz}$ this cover all UWB bandwidth $3.1 \mathrm{GHz}-10.6 \mathrm{GHz}$, and note that after load CSRR to the Vivaldi antenna the gain at low frequency was improved and thus, UWB Vivaldi antenna becomes with band notch WLAN band.

\section{Conflict of interest}

The authors confirm that the publication of this article cause no conflict of interest.

\section{References}

1. Federal Communications Commission (2002). First Report and Order, Revision of part 15 of the Commission's Rule Regarding Ultra-Wideband.

2. G.R. Aiello and G.D. Rogerson, (2003). "Ultra-wideband wireless systems,' IEEE Microw. Mag., vol.4, no.2, pp.36-47, June.

3. N. Chahat, M. Zhadobov, R. Sauleau, and K. Ito, (2011). "A compact UWB antenna for on-body applications,',IEEE Trans. Antennas Propag., vol 59, no. 4, pp. 11231131, Apr.

4. P. J. Gibson, (1979). "The Vivaldi aerial," IEEE 9th European Microwave Conference, pp. 101-105, Sept.

5. Bin Zhou; and Tie-Jun Cui (2011). 'Directivity enhancement to Vivaldi antennas using compactly anisotropic zeroindex metamaterials". IEEE Antenna Wireless Propag. Letters., vol.10, pp.326329.

6. J. Wu, Z. Nie, and Q.-H. Liu, (2014). “A printed UWB Vivaldi antenna using stepped 
connection structure between slotline and tapered patches." IEEE Antennas Wireless Propag Lett, vol. 13, pp. 698-701.

7. Hyung-Seok Choi, Tae-Woo Kim, HeeYong Hwang, and Kyung Choi, (2014). "An UWB Antenna Design with Adjustable Second Rejection Band Using SIR," IEEE Trans. Antennas Magnetic., vol. 50, pp. 7022604-7022604, February.

8. Qing-Xin Chu, Chun-Xu Mao, and He Zhu, (2013). "A Compact Notched Band UWB Slot Antenna with Sharp Selectivity and Controllable Bandwidth," IEEE Trans. Antennas Propag., vol. 61, pp.3961-3966, August.

9. Jawad Y. Siddiqui, Chinmoy Saha, Yahia M. M. Antar, (2015). "Compact Dual-SRRLoaded UWB Monopole Antenna with Dual Frequency and Wideband Notch Characteristics," IEEE Antennas and Wireless propagation Letters., vol.14, pp.100-103.

10. Jawad Y. Siddiqui, Chinmoy Saha, Yahia M. M. Antar, (2014). "Compact SRR Loaded UWB Circular Monopole Antenna with Frequency Notch Characteristics," IEEE Trans. Antennas Propag., vol.62, pp. 4015-4020, August.

11. Matthias John, Max J. Ammann, (2008)." UWB Vivaldi Antenna Based on A spline Geometry with frequency Band-Notch" Antennas and propagation Society International Symposium,2008. APS2008.IEEE.

12. Yanhui $\mathrm{Xu}$, Jianpeng Wang, Lei Ge, Xuedao Wang, and Wen Wu, (2017). "Design of a notched-band Vivaldi antenna with high selectivity," IEEE Antennas and Wireless Propagation Letters., vol.17, no.1, pp.62-65. 